\title{
Use of Tablet Technology: A Pilot Program for Graduate Students in Speech-Language Pathology
}

Taylor N. Hansen

University of Nebraska at Omaha, taylorhansen@unomaha.edu

Abby L. Bjornsen

University of Nebraska at Omaha, abjornsen@unomaha.edu

Shari L. DeVeney

University of Nebraska at Omaha, sdeveney@unomaha.edu

DOI: doi.org/10.30707/TLCSD1.1Hansen

Follow this and additional works at: https://ir.library.illinoisstate.edu/tlcsd

Part of the Other Teacher Education and Professional Development Commons, and the Special Education and Teaching Commons

\section{Recommended Citation}

Hansen, Taylor N.; Bjornsen, Abby L.; and DeVeney, Shari L. (2017) "Use of Tablet Technology: A Pilot Program for Graduate Students in Speech-Language Pathology," Teaching and Learning in Communication Sciences \& Disorders: Vol. 1: Iss. 1, Article 2.

DOI: doi.org/10.30707/TLCSD1.1Hansen

Available at: https://ir.library.illinoisstate.edu/tlcsd/vol1/iss1/2

This Scholarship of Teaching and Learning Research is brought to you for free and open access by ISU ReD: Research and eData. It has been accepted for inclusion in Teaching and Learning in Communication Sciences \& Disorders by an authorized editor of ISU ReD: Research and eData. For more information, please contact ISUReD@ilstu.edu. 


\title{
Use of Tablet Technology: A Pilot Program for Graduate Students in Speech- Language Pathology
}

\author{
Abstract \\ The study purpose was to examine the associations between a 15-week intervention pilot program and a \\ variety of self-reported measures of tablet technology use for graduate students in speech-language \\ pathology (SLP) across classroom and clinical contexts. Participants were millennial-aged students $(n=$ \\ 9) in an accredited SLP graduate program in the Midwest. Participants each received an iPad Air 2 tablet \\ and engaged with other participants and clinical educators to regularly discuss and demonstrate tablet \\ use relative to classroom environments and evidence-based clinical contexts. Participants were \\ anonymously surveyed at four different intervals using a 30-item questionnaire that addressed frequency, \\ competency, and use of iPad applications. Surveys were administered at the beginning, middle, and end \\ of the semester, and at one-month follow-up. Data were analyzed both quantitatively and qualitatively in a \\ mixed-methods design. Quantitatively, the frequency of use for clinical and academic purposes increased \\ over the course of participation, but only significantly for clinical purposes. Qualitative data was organized \\ into three primary themes: (1) frequency of iPad use for clinical purposes; (2) perceived competence with \\ clinically-related iPad use; and (3) overall experience with the iPad Pilot Program. Results and \\ recommendations regarding the use of tablet technology are discussed.
}

\section{Keywords}

Apps, applications, clinic, evidence-based practice, graduate students, iPad, tablet, technology

\section{Cover Page Footnote}

The authors would like to acknowledge grant funding awarded to the first author by the University of Nebraska at Omaha (UNO) Fund for Undergraduate Scholarly Experiences (FUSE). Funding for iPads was provided by a generous donation from the Southwest Omaha Sertoma to the UNO Speech-LanguageHearing Clinic. 


\section{Introduction}

Since the first iPad was introduced in 2010, over 40 million have been sold worldwide (DeCurtis \& Ferrer, 2011) and over 500,000 applications are available for download (Apple Inc., 2014). Millennials, individuals born between 1980 and 2000 are often assumed to be able to incorporate the use of tablet technology, including iPads, "as a 'sixth sense' and as a fully integrated means of interacting with the world" (Hershatter \& Epstein, 2010, p. 211). However, proponents of a counter argument caution against embracing this general assumption about millennials. Bennett, Maton, and Kervin (2008) noted that immersion in a technology-rich culture does not readily translate into a sophisticated knowledgebase and the development of radically different learning preferences compared with earlier generations. Students' use and skills with tablet technology should not be assumed to be uniform or exceptional across younger generations (Bennett et al., 2008).

Regardless of their technical savvy, for the field of speech-language pathology (SLP), millennials are soon going to make up a large proportion of clinicians in the field (Hershatter \& Epstein, 2010). Currently, most students entering SLP graduate programs are millennials (McCready, 2011). In addition, practicing SLPs' integration of technology for clinical interactions continues to grow (Brundage \& Hancock, 2015; Carey, O'Brian, Lowe, \& Onslow, 2014; Halpern, et al., 2012; Ingram, Bunta, \& Ingram, 2004; Kurland, Wilkins, \& Stokes, 2014; Tanner, 2011).

Clinical educators and graduate faculty members may erroneously presume competence for use of tablet technology by millennial graduate students. In a recent survey of 24 first-year, millennial SLP graduate students, fewer than half reported using iPads or other tablet technology, with $21 \%$ reporting lack of perceived competence with technology use (Sutton, 2014). In addition, graduate students enrolled in on-campus clinical experiences generally prefer to utilize in-person supervision over iPad-mediated clinical supervisor interactions (Farrell, et al., 2013).

Evidence would suggest a need to expand graduate curricula in order to keep up with the rapidly growing technology use of the profession. The majority of practicing SLPs reported that their graduate programs did not place adequate emphasis on technology incorporation (Wilson, Raymond, \& Satterfield, 2014). There is a need for specific training to provide SLP graduate students with the knowledge and skills to effectively evaluate and implement technology for clinical use (Sutton, 2014). The American Speech-Language-Hearing Association (ASHA, 2012) noted millennial SLP students need training in use of advanced internet-based transactions and telecommunications, such as those conducted 
through tablet technology. Graduate training programs will be expected to produce professional candidates who can use a variety of different technology-mediated tools in order to effectively evaluate and treat communication disorders (ASHA, 2012). To that end, some training programs have developed focused, systematic ways for their SLP graduate students to approach technology integration in clinical (Harris Brown, Heggs, \& Millican, 2013) and classroom (Friberg, 2012) settings.

SLP graduate students may be encouraged or required to use tablet technology in their clinical work with communication disorder clients. While it may be expected that new SLP graduate students seek guidance from classmates, clinical educators, or faculty members (Harris Brown et al., 2013), it is the responsibility of academic programs to educate students on the use of evidence-based practice (EBP) for both assessment and treatment considerations. The integration of tablet technology into clinical settings creates new EBP challenges, including the use of clinicallyrelevant applications (apps) (Kurland, 2014).

In sum, the classroom landscape is rapidly changing with the increasing instructional use of technology, including the use of tablets for clinical purposes (Miller \& Aaron, 2014). Given recent findings related to perceived lack of competence in the use of tablet technology by SLP graduate students (Sutton, 2014), it is imperative to develop interventions serving to increase competence with technology use as related to the profession. In order to gain a deeper understanding of this phenomenon, it is necessary to include qualitative methodology, which allows for rich elaboration on complex topics (Creswell, 2013; Rubin and Rubin, 2005; Maxwell, 2005; Merriam, 1998). To date, investigations on this topic within the field of speech-language pathology have been quantitative in nature, and have not been intervention-based. Additionally, scant evidence from related disciplines is available for comparison. Therefore, the current study aims to address gaps in the literature through a mixed-methods intervention pilot program.

Three overarching research questions were addressed in the current project:

1) Is an intervention pilot program for tablet technology associated with increases in self-reported frequency of tablet use in classroom and clinical settings for SLP graduate students?

2) Is an intervention pilot program for tablet technology associated with increases in self-reported competence of tablet use in classroom and clinical settings for SLP graduate students?

3) Is an intervention pilot program for tablet technology associated with increases in self-reported awareness of evidence-based practice (EBP) as related to tablet use in clinical settings for SLP graduate students? 


\section{Method}

Participants. Participation was voluntary. Graduate students enrolled in one of three on-campus clinical training courses were invited to apply for participation in the iPad Pilot Program (iPP) by completing a brief survey through Survey Monkey, a free online survey software program and questionnaire tool (available from https://www.surveymonkey.com). Applicants responded to basic demographic questions (e.g., date of birth; current on-campus clinical training level) and wrote a paragraph indicating their rationale for desired participation. Fifteen complete applications were reviewed by one SLP faculty member and two clinical educators. Participation selections were based on two-tier criteria: (a) clinical experience level and (b) quality of stated rationale for participation. Initial selection was based on a desired minimum of three students per clinical experience level (first, second, or third semester), that would result in a total of 10 eligible participants to ensure participation across a variety of experiential levels aligned with the number of iPads available for use in the pilot program. Secondly, each written rationale was blindly reviewed for quality and ranked (1-15) by each of the three reviewers. These rankings were then averaged across reviewers. Next, participants were identified as the three highest ranked within each clinical experience level and the next highest ranked was additionally included for a cohort of 10. One participant opted out of the iPP after the first two weeks due to scheduling constraints, resulting in a total of nine participants (eight females and one male). All participants were millennials (based on dates of birth ranging from 1979 to 1992) enrolled in one of three oncampus clinical training courses in an accredited SLP graduate training program: first semester $(n=3)$, second semester $(n=4)$, and third (final) semester $(n=2)$. Participants were arranged in natural groups with assessment on multiple occasions consistent with a quasi-experimental research design (Kazdin, 2011).

Materials. Experimental materials included the tablets provided to students and facilitating clinical educators, and the survey instrument used.

Tablets. All student participants and the two instructing clinical educators $(\mathrm{n}=11)$ received an iPad Air 2 provided through a private donation to the clinical training program. Initially, 15 clinical and/or academic apps were uploaded to each iPad: Category Therapy - Speech Rehab for Categories (Tactus Therapy Solutions, 2014), Conversation Therapy - Questions for Expressive Language, Pragmatics, \& Cognition (Tactus Therapy Solutions, 2015), Language Therapy -4-in-1 Toolkit for Aphasia Speech Therapy (Tactus Therapy Solutions, 2015), My PlayHome (PlayHome Software, 2015), NedTheNeuron (Kizoom, 2015), Notability (Ginger Labs, 2015), Poplet (Notion, 2014), Proloquo2Go - Symbol-based AAC (AssistiveWare, 2015), Question Therapy 2-in-1 (Tactus Therapy Solutions, 2015), Spaced Retrieval Therapy (Tactus Therapy Solutions, 2013), Speech FlipBook 
Standard (Tactus Therapy Solutions, 2015), Speech Tutor (Synapse Apps, 2015), Super Duper Data Tracker (Super Duper Publications, 2013), Visual Attention Therapy - Cognitive Training(Tactus Therapy Solutions, 2014), and Voice Meter Pro (Andrews, 2014). The initial apps were researched, previewed, and selected at the discretion of the two facilitating clinical educators based on targeted clinical caseloads and potential for academic utility. Student participants added additional apps throughout the semester based on individual clinical assignments and/or classroom needs. The students were allowed to continue use of the iPads for the remainder of their on-campus clinical experiences, which potentially included up to two additional semesters given their stage in the clinical experience progression. Students returned the tablets to the department before beginning their off-campus clinical externships. Participants were only allowed to use the devices for apps that were purchased through the university. For example, there was no Facebook app purchased so students were unable to use this app on the iPads, but student participants could access email and Pinterest because those apps were already procured through the university.

Survey. The first and third authors developed a 30-item questionnaire including 15 Likert-scale statements (see Appendix A) and 15 open-ended questions (see Appendix B). The Likert scale responses varied from 1 "strongly disagree" to 5 "strongly agree." Open-ended questions addressed perception of tablet technology competency, frequency and type of tablet technology use, and feedback regarding the pilot structure and format. Participants completed this survey at four intervals through Survey Monkey, at the beginning of the semester before participation began (Survey 1), at midterm (Survey 2), at the conclusion of the semester (Survey 3 ), and one-month after the conclusion of the semester (Survey 4). For Survey 3 and 4 , one additional open-ended question was included to specifically address participant experiences with the seminar portion of the pilot program. This question was added at the request of the facilitating clinical educators. All survey responses were anonymous and no survey data were shared with the facilitating clinical educators until after the conclusion the study. Participating students were informed verbally and in writing of this disclosure policy so as to encourage candid responses. A reminder email was sent by the first author the week before each survey was available. Two additional emails were sent during the week each survey was available. All participants responded to each survey.

Program procedures. Participants attended group seminars with the clinical educators for one hour each week throughout the pilot semester (15 weeks of a 16week semester). The key student learning outcomes identified by the facilitating clinical educators prior to initiation of the program included the following: (1) increase frequency of clinical use of tablet technology; (2) increase perceived 
competence for clinical use of tablet technology; and (3) increase awareness of EBP as related to tablet use in clinical settings.

The format evolved over the course of seminar as students gained more independence and self-direction. Initially (first three weeks), participants reviewed articles and blogs related to adult learning models, appropriate app selection, and implementation of EBP with tablet technology use. Students discussed and reviewed assigned readings as a group, as well as through an online discussion board thread. As the pilot progressed, participants worked in small groups to research clinical apps. These small groups convened to share their findings with one another, focusing specifically on strategic use of apps in clinical settings. After the first six weeks, the seminar became more student-driven, with a focus on sharing experiences and successes with app use. The role of clinical educators was to facilitate discussions, emphasizing EBP.

\section{Results}

Quantitative. Descriptive statistics (e.g., means, standard deviations, and response ranges) and inferential statistics (e.g., Friedman tests) were calculated for the Likert scale survey responses obtained at all four intervals (see Table 1). Participant responses to the Likert scale survey items were analyzed by conducting a Friedman Test, a nonparametric alternative to repeated measure analysis of variance (ANOVA), using IBM SPSS Version 22.0 (IBM Corp., 2013). A Friedman test with post hoc pairwise comparisons was utilized to calculate differences between the distributed data from the 15-Likert scale response items across the four survey data collection points. A Bonferroni correction was used to compare participant responses across individual stimulus items to determine response items for which participant responses changed significantly over time (see Table 2).

Participant survey responses were statistically significantly varied at the different time points during the pilot: $\chi^{2}(3)=26.291, p<.0001$. Pairwise comparisons were performed with a Bonferroni correction for multiple comparisons. Responses were significantly different between survey $1(M d n=$ 
Table 1. Participant responses to quantitative survey questions for Survey 1 (pre-iPP program), Survey 2 (mid-program), Survey 3 (post-program), and Survey 4 (one month follow up).

\begin{tabular}{|c|c|c|c|c|c|c|c|c|}
\hline Item & $\begin{array}{l}\text { Survey } \\
1 \\
M\end{array}$ & $\begin{array}{l}\text { Survey } \\
1 \\
S D\end{array}$ & $\begin{array}{l}\text { Survey } \\
2 \\
M\end{array}$ & $\begin{array}{l}\text { Survey } \\
2 \\
S D\end{array}$ & $\begin{array}{l}\text { Survey } \\
3 \\
M\end{array}$ & $\begin{array}{l}\text { Survey } \\
3 \\
S D\end{array}$ & $\begin{array}{l}\text { Survey } \\
4 \\
M\end{array}$ & $\begin{array}{c}\text { Survey } \\
4 \\
S D\end{array}$ \\
\hline 1. I frequently use tablet technology for clinical interactions. & 2.36 & 0.92 & 4.50 & 0.05 & 4.63 & 0.52 & 3.56 & 1.24 \\
\hline 2. I frequently use tablet technology for clinical preparations. & 2.18 & 0.87 & 4.13 & 0.35 & 4.25 & 0.46 & 3.56 & 1.24 \\
\hline 3. I frequently use tablet technology for clinical data collection. & 1.82 & 1.08 & 2.50 & 1.31 & 1.88 & 1.36 & 1.78 & 0.97 \\
\hline 4. I frequently use tablet technology for academic coursework. & 2.45 & 1.57 & 3.50 & 1.07 & 3.63 & 1.30 & 3.56 & 0.88 \\
\hline $\begin{array}{l}\text { 5. I am aware of strategies for facilitating evidence-based practice through } \\
\text { the use of tablet technology in clinical interactions. }\end{array}$ & 3.18 & 0.60 & 4.25 & 0.46 & 4.63 & 0.35 & 4.44 & 0.53 \\
\hline 6. I am aware of a variety of applications for clinical use. & 3.27 & 0.79 & 4.50 & 0.53 & 4.88 & 0.36 & 4.50 & 0.53 \\
\hline 7. I am aware of a variety of applications for use with academic coursework. & 3.36 & 1.21 & 4.25 & 0.71 & 4.13 & 0.83 & 4.00 & 0.71 \\
\hline $\begin{array}{l}\text { 8. I am flexible with my use of tablet technology such that I can use a variety } \\
\text { of applications for a variety of clinical purposes. }\end{array}$ & 2.82 & 1.08 & 4.25 & 0.46 & 4.13 & 0.36 & 4.22 & 0.44 \\
\hline $\begin{array}{l}\text { 9. I am flexible with my use of tablet technology such that I can use a variety } \\
\text { of applications for a variety of academic coursework purposes. }\end{array}$ & 3.09 & 1.38 & 3.63 & 1.06 & 3.50 & 0.76 & 3.78 & 0.97 \\
\hline 10. I feel competent using tablet technology for clinical interactions. & 2.91 & 0.94 & 4.25 & 0.46 & 4.50 & 0.53 & 4.22 & 0.44 \\
\hline 11. I feel competent using tablet technology for clinical preparations. & 2.91 & 0.92 & 4.13 & 0.36 & 4.25 & 0.46 & 4.22 & 0.67 \\
\hline 12. I feel competent using tablet technology for clinical data collection. & 2.36 & 0.92 & 2.88 & 1.25 & 2.50 & 1.41 & 2.78 & 1.48 \\
\hline 13. I feel competent using tablet technology for academic coursework & 3.45 & 1.04 & 3.88 & 0.99 & 3.88 & 0.99 & 3.78 & 0.97 \\
\hline $\begin{array}{l}\text { 14. I feel comfortable exploring unfamiliar tablet technology applications on } \\
\text { my own. }\end{array}$ & 3.36 & 1.57 & 4.13 & 0.36 & 3.88 & 0.36 & 4.33 & 0.50 \\
\hline $\begin{array}{l}\text { 15. I feel comfortable finding additional uses for tablet technology applications } \\
\text { other than those described by the application developers. }\end{array}$ & 3.18 & 1.40 & 3.75 & 1.04 & 3.88 & 0.64 & 4.13 & 0.35 \\
\hline
\end{tabular}


Table 2. After post hoc pairwise comparisons with a Bonferroni correction, mean differences in participant survey item responses compared to baseline self-reporting at Survey 1 (significant differences indicated with an asterisk). Response items not listed were not significantly different across any survey comparison.

\begin{tabular}{|c|c|c|c|}
\hline Item & $\begin{array}{l}\text { Survey } 1 \text { to } \\
\text { Survey } 2\end{array}$ & $\begin{array}{l}\text { Survey } 1 \\
\text { to } \\
\text { Survey } 3\end{array}$ & $\begin{array}{l}\text { Survey } 1 \\
\text { to Survey } \\
4\end{array}$ \\
\hline $\begin{array}{l}\text { 1. I frequently use tablet technology for clinical interactions. } \\
\text { 2. I frequently use tablet technology for clinical preparations. } \\
\text { 3. I frequently use tablet technology for clinical data collection. } \\
\text { 6. I am aware of a variety of applications for clinical use. } \\
\text { 10. I feel competent using tablet technology for clinical interactions. }\end{array}$ & $\begin{array}{l}0.016^{*} \\
0.040^{*} \\
0.156 \\
0.199 \\
0.121\end{array}$ & $\begin{array}{l}0.006^{*} \\
0.022^{*} \\
0.006^{*} \\
0.008^{*} \\
0.016^{*}\end{array}$ & $\begin{array}{l}0.395 \\
0.488 \\
0.054 \\
0.599 \\
0.093\end{array}$ \\
\hline
\end{tabular}


$1.07)$ and survey $2(M d n=3.00)(p<0.001)$; between survey 1 and survey $3(M d n$ $=3.23)(p<0.001)$; and between survey 1 and survey $4(M d n=2.70)(p<0.003)$. Significant differences were not noted between surveys 2 and 3, surveys 3 and 4 , or surveys 2 and 4.

Participant responses that were statistically significantly different across one or more survey times were as follows: Item 1 ( $p=.016$ from Survey 1 to $2 ; p=0.006$ from Survey 1 to 3), Item 2 ( $p=0.40$ from Survey 1 to $2 ; p=0.022$ from Survey 1 to 3 ), Item 3 ( $p=0.006$ from Survey 1 to 3 ), Item 6 ( $p=0.008$ from Survey 1 to 3 ), and Item 10 ( $p=0.016$ from Survey 1 to 3$)$. For these items, the majority of participants reported increased competence from the beginning of the semester (survey 1) to the end (survey 3 ), indicated by the following mean rankings for survey 1 for significantly different survey times: Item 1 (Mean $=1.19$ for Survey 1, 3.12 for Survey 2, and 3.31 for Survey 3), Item 2 (Mean = 1.13 for Survey 1, 3.06 for Survey 2, and 3.19 for Survey 3), Item 3 (Mean = 1.19 for Survey 1 and 3.31 for Survey 3), Item 6 (Mean = 1.38 for Survey 1 and 3.44 for Survey 3), and Item 10 (Mean $=1.25$ for Survey 1 and 3.19 for Survey 3). Participant responses between survey 1 and survey 3 were the most significantly different than for any other survey pairings.

Qualitative. Participant responses to open-ended questions were uploaded into QSR International's NVivo 10 Software (NVivo, 2014) and analyzed by two trained researchers (the first and second authors). Following procedures suggested by Gibbs (2008) and Kvale (1996), researchers initially read two transcripts independently to create a list of codes, which were then discussed to achieve consensus and create a codebook. Based on the codes from these initial transcripts, the researchers modified the codebook to include operational definitions of each code in accordance with the data described by it. Researchers then used this codebook in coding two additional transcripts, and met to discuss and achieve consensus. This process resulted in adjustments, which was iteratively revised and then used to recode initial interviews. Final codes were organized into overarching themes. After all discrepancies were discussed, the researchers independently analyzed the remaining transcripts with the updated codebook and met to come to agreement on any discrepancies.

Finally, the results of qualitative data analysis were organized into three primary themes, aligning with the stated purposes of the current study. The discussion of each theme below will be illustrated by direct participant quotes extracted from their narrative responses to open-ended survey questions.

Frequency of use. Participants responded to survey questions regarding the frequency of their iPad use for both clinical purposes across all four survey 
administrations. In order to determine changes in frequency of iPad use from the beginning to the end of the pilot, independent raters examined the number of participants reporting iPad use between the first and fourth survey administrations.

Data was collected from participants regarding their clinical iPad use in three areas: 1) clinical preparation; 2) clinical interaction; and 3) clinical data collection. The most substantial change emerged for use of iPad for clinical interaction, with the number of participants reporting such use doubling from survey $1(n=3)$ to survey $4(n=6)$. As one student mentioned: "I use tablet technology every week for clinic (1 hour per week). I love that it gives visual and auditory feedback.",

Perceived competence. Participants responded to survey questions regarding their perceived feelings of competence versus incompetence of their iPad use for clinical purposes across all four survey administrations. In order to determine changes in competency with iPad use from the beginning to the end of the pilot, independent raters compared responses regarding iPad competence/incompetence between the first and fourth survey administrations. The number of participants reporting feelings of incompetence with clinical iPad use at survey $1(n=6)$ substantially decreased by survey $4(n=1)$. As one participant noted at survey 1: "For clinical purposes, I do not feel competent in using applications for therapy at this time. I feel I need to do more investigating!" This statement contrasted with a participant response at survey 4: "...I feel a lot more confident in my competency compared to the beginning of the study. I am able to implement appropriate applications to target objectives/goals."

Pilot evaluation: During all four survey administrations, participants responded to questions regarding their general experience with the pilot relative to EBP of technology use in clinical settings. A qualitative examination of trends in participant responses across the duration of the project revealed that the majority of students reported positive experiences in the pilot. One participant noted: "...Ifeel that the iPad pilot program has better prepared me as a clinician by improving my skills with critical thinking, creativity, collaboration, and technology. In a world where technology is becoming increasingly prevalent, it's exciting to know that I am gaining cutting edge, hands-on experience with tools that will serve a variety of clients in a variety of ways." A small number of participants offered concrete suggestions for future semesters: "...I think the program could be even better if we bring in professionals to talk about apps they use with clients." 


\section{Discussion}

The purpose of this study was to examine the association of an intervention pilot program with student participants' self-reported measures of frequency of use and perceived competence with use of tablet technology in classroom and clinical settings. In support of ASHA's (2012) forecast for the profession, and Sutton's (2014) observation that targeted technology training was needed at the graduate level, participants in the current study indicated increases in both the frequency of clinical tablet use and perceived competence related to clinical use of tablet technology.

Clinical context. Participants reported significant increases in tablet use for clinical preparation, clinical interactions, and data collection. In addition, the indication by participants that clinical iPad use did not replace all therapy-related activities was consistent with previous recommendations that iPad use for clinical supervision should not be used at the complete exclusion of person-to-person interaction (Farrell et al., 2013). Twice as many participants reported using an iPad for clinical purposes at survey 4 versus survey 1 . Regardless of previous experience using an iPad for any purpose, the clinical setting was a novel one for all participants involved in the pilot. As such, participants previously familiar with iPad utilization had to familiarize themselves with use of this technology in a clinical setting, and participants lacking previous familiarity with the iPad were faced with the dual task of gaining familiarity with both the technology and the setting. It is quite possible that that familiarity breeds comfort, which may have contributed to the higher frequencies of clinical use reported by participants at the close of the pilot as opposed to the outset.

Although participants reported increased frequency of iPad use for clinical preparation, clinical interaction, and data collection, increased competence was reported exclusively in the realm of clinical interaction. One possible explanation is that participants likely acquired exposure to a variety of clinical interactions during their undergraduate experiences through observation hours and simulated cases, with less emphasis placed upon treatment planning for a variety of clients, leading them to be more comfortable implementing new procedures with clinical interaction over clinical preparation. In addition, while participants certainly learned about data collection in their undergraduate programs, their framework for this process was likely quite structured. The implementation of tablet technology into clinical data collection was likely a significant departure from their initial framework for data collection in terms of novelty and creativity. 
Participant reports of perceived incompetence with clinical iPad use substantially decreased from survey 1 to survey 4. It is plausible that this decrease in perceived incompetence could be due to the pilot through interventions such as reading and discussing empirical journal articles about professional iPad use, as well as both small and large group discussions that entailed sharing successful experiences, tips for effective use, and suggestions regarding applications. The knowledge and applied experience participants acquired through the pilot intervention may have contributed to perceptions of increased clinical competence.

Participants also reported developing an increased awareness of a variety of clinical apps suitable for clinical use, noting an increased sense of competence in using tablet technology for clinical interactions. This hypothesis is supported through participant responses to Item 5, which addressed EBP: I am aware of strategies for facilitating evidence-based practice through the use of tablet technology in clinical interactions. This finding supports previous research (Harris Brown et al., 2013) outlining an EBP educational paradigm incorporating a variety of apps available through tablet technology to enhance and augment therapeutic interactions.

Academic context. Although general gains in flexibility and frequency of use were noted across the pilot program experience, other measures related to generalization of use to academic settings showed a more unchanging pattern across sampling times. Perhaps participants used the iPads more in class just because they had them available. Having more ready access to the technology likely made it more enticing to use and the participants more likely to download and try out different apps as an exploratory exercise that did not necessarily result in increases in competence, just exposure.

Compared to the significant changes in participant responses noted across the clinical context, the academic context denoted much more modest response variations. One likely explanation for this discrepancy could be related to the program facilitators. Their clinical background and interests may have skewed the focus of the weekly seminars directly (e.g., through their own interactions and contributions to discussions) and/or indirectly (e.g., due to the students' expectations based on typical clinic-related interactions with them). Due to their clinical roles, they have a much more intimate familiarity with clinical settings over academic classroom settings and this very likely influenced the nature of the pilot program seminars. As an extension of this clinical focus, it is noteworthy that the majority of the 15 initial apps were not academically oriented. Only two, Notability and Poplet, had potential use in academic settings. 
Pilot program success. Participants largely indicated that their overall experience with the pilot was positive, with many reporting that they appreciated discussing and sharing ideas for iPad use within the pilot group perhaps most of all. Given that pilot participants were millennials, it is plausible that their general technological prowess (Hershatter \& Epstein, 2010) enabled them to quickly discover how to use the iPad in novel ways, effectively sharing their skills with one another, resulting in positive responses.

In terms of survey responses from which program success data were extracted, it was notable that mean scores for many data points peaked at the time of Survey 3, then decreased at the time of Survey 4. This phenomenon may be attributed to survey timing. Survey 3 was administered at the end of the spring semester and coincided not only with the conclusion of direct instruction and facilitated discussions about tablet technology use, but also the end of the semester's oncampus clinical experience. The timing of Survey 4, at one-month follow up, came at the beginning of summer on-campus clinical experiences. It is possible that as students began new clinical interactions with unfamiliar clients, their perceived self-competence with tablet technology use decreased. Additionally, their lack of structured interactions around tablet technology use may have contributed to decreased feelings of competence and/or frequency of use.

Limitations and future directions. There are several limitations in the current project. Although the small sample size $(n=9)$ is justified by the pilot-nature of this early discovery project, it would be ideal to complete this study with a larger sample size to ensure saturation of participant responses, and to obtain a more complete picture of changes in clinical use of tablet technology across a more substantial number of students. While data collection is not ongoing in the current project, future research on this topic might include a longitudinal design in which the same participants would take part in this intervention seminar across all three clinical semesters in their program of study.

Another limitation concerns the potential overlap in participant perception of clinical competence for clinical preparation versus clinical interaction. Although participants were queried about competence in both areas, there may be overlap between the two (e.g., some degree of training in clinical preparation would likely be necessary prior to utilizing an app in a structured clinical setting). Future researchers may do well to be more explicit in assessing for competence in clinical preparation versus clinical interaction, perhaps specifically inquiring as to how one informs the other. 
An additional limitation concerned the anonymous nature of Survey Monkey responses. While this procedure facilitated both confidentiality and comparison of survey results overall, the capacity to track individual student growth throughout the pilot was not possible due to lack of assigned identifier codes. In future studies, it would be ideal to assign each participant an arbitrary code to maintain anonymity while allowing for determination of program progression for each participant (e.g., number of semesters completed). This could enhance researcher capacity to offer recommendations specific to the developmental level of the student.

After the one-month follow up survey, the anonymous survey results were available to be shared with the facilitating instructors. Student participants knew the results could eventually be shared with the instructors which may have influenced their responses. Although this factor cannot be completely eliminated as a potential confound, the scenario is similar to the university's course evaluation process conducted at the end of semester. Both forms included Likert-scale and open-ended response formats and were completed online. The policy of this university, as students are generally aware, is to share the response content with faculty instructors when more than five students are enrolled in the course. Because of the students' general familiarity with this course evaluation policy, it is unlikely that their responses were influenced, but the authors acknowledge that the possibility cannot be excluded. In future studies, researchers could elect not to share the responses with instructors and communicate this decision to student participants.

As noted earlier in the discussion, an implicit bias toward clinical instruction by the program facilitators may have limited tablet technology emphasis on academic contexts. In future studies, including facilitating instructors with a more academiccontent preference may result in a balance of response patterns across the two contexts. However, future researchers should remain mindful that a focus on the clinical use of technology is aligned with the ASHA (2012) graduate training program expectations although no such expectations were noted by the professional association for classroom technology use.

Another limitation involved the lack of available information regarding the nature and substance of student mentoring and meetings. Specific content related to this aspect of the pilot program was not included in the present early discovery research, which does limit replication efforts of other investigators. Investigators interested in further exploration of this important area are encouraged to consider inclusion of more detailed descriptions and accounts of the student mentoring and meeting experiences.

Whether investigating tablet use in clinical settings, classroom settings, or both, it 
is recommended that future researchers collect data on the length of usage (e.g., minutes, hours). The lack of such data was another limitation in the current project, and tracking length of use in future research might provide information about the intensity of technology use. Finally, future investigators may consider a comparision group consisting of students who purchased their own iPads in order to determine if the 'free' nature of the expensive device influenced student responses regarding the pilot program's success. It is possible that provision of the device itself and the special attention of the meetings affected some of the positive results in the present study.

Recommendations for implementation. The following implementation guidelines may assist other graduate program faculty and clinical educators in developing similar technology-based curriculum in response to the growing trend of technology use in clinical practice:

1. Identify key personnel to serve as facilitating instructors, preferably a small cohort including representation from both clinical and academic educators.

2. Determine key learner outcomes to support a goal-oriented, purposeful experience.

3. Consider the best fit for delivery. Given the unique circumstances across graduate programs, variations in delivery are expected. For example, one program could propose a strictly volunteer experience, another could offer as a for-credit course or a pass/no pass option, or still another program could incorporate it into an existing seminar or course offering.

4. Determine target student audience. Again, based on unique program characteristics, there is not a "one size fits all" suggestion, but rather an invitation to mindfully consider the most effective, convenient, and/or appropriate stage in the training process to introduce.

5. Research, preview, and select a small group (10-15) of initial apps.

6. Research, preview, and select a number of sources (e.g., articles, blogs) related to adult learning models, appropriate app selection, and implementation of EBP with tablet technology use. Creating discussion questions related to each may encourage and guide initial dialogues.

7. Begin the experience with more guided instructor-led interactions, but shift of over the course of the experience to a more independent studentled facilitation.

8. Identify professionals in the field who may be willing to provide guest lectures in order to advance application of knowledge to "real world" clinical practice beyond the graduate experience.

9. Monitor student progress throughout the experience. 
10. Solicit and act upon feedback from student participants during and after the experience in order to maximize student learning potential and remove possible barriers to the learning process.

\section{Conclusion}

Over the course of this 15-week intervention pilot program, success was demonstrated in the attainment of the three student learning outcomes. The majority of participants exhibited statistically significant increases in both frequency of clinical use of tablet technology, as well as perceived competence with use. Students also reported being more aware of strategies for facilitating EBP through the use of tablet technology. In conclusion, based on the reported experiences of the current study participants, the pilot was deemed successful. Graduate program faculty in SLP may do well to consider initiating a similar pilot as a means of structured curricular response to the growing trend of technology use in clinical practice.

\section{References}

American Speech-Language-Hearing Association (2012). Trends and forecasts. Retrieved fromwww.asha.org/Events/SLP-Summit-Trends-Forecasts/

Andrews, P. (2014). Voice Meter Pro (Version 1.5) [Mobile application software]. Retrieved from http://itunes.apple.com

Apple Inc. (2014). Ipad air applications. Retrieved from http://www.apple.com/ipad-air/app-store/

AssistiveWare. (2015). Proloquo2Go - Symbol-based AAC (Version 4.2) [Mobile Application software]. Retrieved from http://itunes.apple.com

Bennett, S. J., Maton, K. A. \& Kervin, L. K. (2008). The 'digital natives' debate: a critical review of the evidence. British Journal of Educational Technology, 39 (5), 775-786.

Brundage, S.B., \& Hancock, A.B. (2015). Real enough: Using virtual public speaking environments to evoke feelings and behaviors targeted in stuttering assessment and treatment. American Journal of Speech-Language Pathology, 24, 139-149. doi:10.1044/2014_AJSLP-14-0087

Carey, B., O'Brian, S., Lowe, R., \& Onslow, M. (2014). Webcam delivery of the Camperdown program for adolescents who stutter: A phase II trial. Language, Speech, and Hearing Services in Schools, 45, 314-324. doi:10.1044/2014_LSHSS-13-0067

Creswell, J. W. (2013). Research design: qualitative, quantitative, and mixed method approaches (4th ed.). Thousand Oaks, California: Sage Publications. 
DeCurtis, L.L. \& Ferrer, D. (2011, November). Embracing iPad technology with toddlers using traditional therapy techniques. Presented at the American Speech-Language-Hearing Association Annual Convention, San Diego, CA.

Farrell, C. F., Lindstedt, D. E., Anderkin, K., Burdett, E. C., Lyding, B., \& Sarge, M. (2013). Use of the iPad for Graduate Clinician Distance Supervision: A Preliminary Study. Perspectives on Administration and Supervision, 23(2), 59-69. doi:10.1044/aas23.2.59

Friberg, J.C. (2012). Using iPad technologies to support teaching and learning in CSD. Perspectives on Issues in Higher Education, 15, 16-21. doi:10.1044/ihe15.1.16

Gibbs, G. (2008). Analyzing Qualitative Data. Thousand Oaks: Sage Publications Ltd. Ginger Labs. (2015). Notability (Version 6.0.0) [Mobile application software]. Retrieved from http://itunes.apple.com

Halpern, A.E., Ramig, L.O, Matos, C.E.C., Petska-Cable, J.A., Spielman, J.L., Pogoda, J.M, McFarland, D.H. (2012). Innovative technology for the assisted delivery of intensive voice treatment (LSVT®LOUD) for Parkinson disease. American Journal of Speech-Language Pathology, 21, 354-367. doi:10.1044/1058-0360(2012/11-0125

Harris Brown, K., Heggs, A., Millican, K. (2013). Project using iPads for clinical supervision. Perspectives on Administration and Supervision, 23(2), 4-11. doi:10.1044/aas23.1.4

Hershatter, A. \& Epstein, M. (2010). Millennials and the world of work: An organization and management perspective. Journal of Business and Psychology, 25, 211-223. doi: 10.1007/s10869-010-9160-y

IBM Corp. (2013). IBM SPSS Statistics for Windows, Version 22.0. Armonk, NY: IBM Corp. Ingram, K., Bunta, F., \& Ingram, D. (2004). Digital data collection and analysis application for clinical practice. Language, Speech, and Hearing Services in Schools, 35, 112-121. doi:10.1044/01611461(2004/013)

Kazdin, A. E. (2011). Single-case research designs: Methods for clinical and applied settings (2nd ed.). New York, New York: Oxford University Press.

Kizoom, Inc. (2015). NedTheNeuron (Version 1.4.2) [Mobile application software]. Retrieved from http://itunes.apple.com

Kurland, J. (2014). iRehab in Aphasia Treatment. Seminars in Speech and Language, 35, 3-4. doi:10.1055/s-00331362989.ISSN 0734-0478

Kurland, J., Wilkins, A. R., \& Stokes, P. (2014). iPractice: Piloting the effectiveness of a tablet-based home practice program in aphasia treatment. Seminars in Speech and Language, 35, 51-63. doi:10.1055/s-00331362991.ISSN 0734-0478

Kvale, S. (1996). InterViews: An Introduction to Qualitative Research. Thousand 
Oaks, CA: Sage Publications.

Maxwell, J. A. (2005). Qualitative Research Design: An Interactive Approach. Thousand Oaks, CA: Sage Publications.

McCready, V. (2011, April 26). Generational issues in supervision and administration. The ASHA Leader. Retrieved from http://www.asha.org/publications/leader/2011/110426/generational-issuesin-supervision-and-administration.htm

Merriam, S. B. (1998). Qualitative Research and Case Study Applications in Education. Jossey-Bass: San Francisco, CA.

Miller, C., \& Aaron, D. (2014). The new landscape of mobile learning: redesigning education in an app-based world. New York, NY: Taylor and Francis.

Notion. (2014). Poplet (Version 2.1) [Mobile application software]. Retrieved From http://itunes.apple.com

NVivo 10 [Software program]. (2014). Retrieved from http://www.qsrinternational.com

PlayHome Software Ltd. (2015). My PlayHome (Version 2.6.0) [Mobile application software]. Retrieved from http://itunes.apple.com

Rubin, H. J. \& Rubin, I. S. (2005). Qualitative interviewing: The art of hearing data. Thousand Oaks, CA: Sage Publications.

Super Duper Publications (2013). Super Duper Data Tracker (Version 2.0.4) [Mobile application software]. Retrieved from http://itunes.apple.com

Sutton, M.S. (2014, November). What SLP graduate students need to know about technology in therapy. Poster presentation at the American SpeechLanguage-Hearing-Association (ASHA) Annual Convention, Orlando, FL.

Synapse Apps, LLC. (2015). Speech Tutor (Version 2.05) [Mobile application software]. Retrieved from http://itunes.apple.com

Tactus Therapy Solutions Ltd. (2014). Category Therapy - Speech Rehab for Categories (Version 1.03) [Mobile application software]. Retrieved from http://itunes.apple.com

Tactus Therapy Solutions Ltd. (2015). Conversation Therapy - Questions for Expressive Language, Pragmatics, \& Cognition (Version 1.04) [Mobile application software]. Retrieved from http://itunes.apple.com

Tactus Therapy Solutions Ltd. (2015). Language Therapy - 4-in-1 Toolkit for Aphasia Speech Therapy (Version 2.02) [Mobile application software]. Retrieved from http://itunes.apple.com

Tactus Therapy Solutions Ltd. (2015). Question Therapy 2-in-1 (Version 1.02) [Mobile application software]. Retrieved from http://itunes.apple.com

Tactus Therapy Solutions Ltd. (2013). Spaced Retrieval Therapy (Version 1.02) [Mobile application software]. Retrieved from http://itunes.apple.com

Tactus Therapy Solutions Ltd. (2015). Speech FlipBook Standard (Version 1.05) 
[Mobile application software]. Retrieved from http://itunes.apple.com Tactus Therapy Solutions Ltd. (2014). Visual Attention Therapy - Cognitive Training (Version 1.05) [Mobile application software]. Retrieved from http://itunes.apple.com

Tanner, M. (2011, May). Technology's emerging frontier in speech-language pathology, part 1 [Web log]. Retrieved from http://blog.asha.org/2011/05/26/technologys-emerging-frontier-in-speechlanguage-pathology-part-1/

Wilson, B., Raymond, C.A., \& Satterfield, B. (2014, November). Perceptions and usage of current technology by speech-language pathologists. Poster presentation at the American Speech-Language-Hearing-Association (ASHA) Annual Convention, Orlando, FL. 


\section{Appendix A: Likert-scale survey questions}

Please indicate your response to items 1-15 using the following scale:

$1=$ Strongly Disagree; $2=$ Disagree; $3=$ Neutral; $4=$ Agree; $5=$ Strongly Agree

1. I frequently use tablet technology for clinical interactions.

2. I frequently use tablet technology for clinical preparations.

3. I frequently use tablet technology for clinical data collection.

4. I frequently use tablet technology for academic coursework.

5. I am aware of strategies for facilitating evidence-based practice through the use of tablet technology in clinical interactions.

6. I am aware of a variety of applications for clinical use.

7. I am aware of a variety of applications for use with academic coursework.

8. I am flexible with my use of tablet technology such that I can use a variety of applications for a variety of clinical purposes.

9. I am flexible with my use of tablet technology such that I can use a variety of application for a variety of academic coursework purposes.

10. I feel competent using tablet technology for clinical interactions.

11. I feel competent using tablet technology for clinical preparations.

12. I feel competent using tablet technology for clinical data collection.

13. I feel competent using tablet technology for academic coursework.

14. I feel comfortable exploring unfamiliar tablet technology applications on my own.

15. I feel comfortable finding additional uses for tablet technology applications other than those described by the application developers. 


\section{Appendix B: Open-ended survey questions}

Please provide your narrative response to questions 1-15 in the space provided. Responses are anonymous, so please be as honest as possible.

1. How frequently do you use tablet technology for clinical interactions? (\# of hours per week) What applications do you use and why?

2. How frequently do you use tablet technology for clinical preparations? (\# of hours per week) What applications do you use and why?

3. How frequently do you use tablet technology for clinical data collection? (\# of hours per week) What applications do you use and why?

4. How frequently do you use tablet technology for academic coursework? (\# of hours per week) What applications do you use and why?

5. Describe your views of tablet technology for clinical and classroom use.

6. Describe your views of tablet technology for classroom use.

7. Describe strategies you use to facilitate evidence-based practice through the use of tablet technology in clinical interactions.

8. Describe how you use tablet technology applications in clinical settings.

9. Describe how you use tablet technology applications for academic coursework.

10. Describe your feelings of competency or incompetency for using tablet technology for clinic (e.g., during clinical interactions, preparation, data collection).

11. Describe your feelings of competency or incompetency for using tablet technology for academic coursework.

12. What areas do you feel most success with tablet technology use? Least? Why?

13. What aspects of tablet technology would you like to learn more about? Why? 
14. Describe your experiences so far with the iPad Pilot Program. What do you like currently about the program? How could the program be improved?

\section{Additional comments?}

